\title{
Design of a Methane Monitoring System for Landfill and Duct Emissions
}

\author{
Federico Hahn1, Gaudencio Grande ${ }^{2}$ \\ ${ }^{1}$ Irrigation Department, Universidad Autonoma Chapingo, Texcoco, México \\ 2IAUIA, Universidad Autonoma Chapingo, Texcoco, México \\ Email: fhahn@correo.chapingo.mx
}

How to cite this paper: Hahn, F. and Grande, G. (2020) Design of a Methane Monitoring System for Landfill and Duct Emissions. Natural Resources, 11, 520-529. https://doi.org/10.4236/nr.2020.1111030

Received: January 16, 2020

Accepted: November 21, 2020

Published: November 24, 2020

Copyright $\odot 2020$ by author(s) and Scientific Research Publishing Inc. This work is licensed under the Creative Commons Attribution International License (CC BY 4.0).

http://creativecommons.org/licenses/by/4.0/ (c) (i) Open Access

\begin{abstract}
Methane is released from waste disposal areas as a result from anaerobic decay of food. Methane causes more greenhouse effects than carbon dioxide so a methane monitoring system is required to warn its release from gas emitting environments. The low explosive limit of methane is $5 \%$ in ambient air, so gas leakage is dangerous and can produce explosions. An entire head monitoring system was built around a MQ-4 methane gas sensor as it is cheap and reliable. The design proves to be flexible enough as it can measure $\mathrm{CH}_{4}$ emissions in ducts, $\mathrm{CH}_{4}$ in landfills at different depths and even in cattle barns. The measuring system head consists of a suction pump, solenoids, and a methane sensor. Measurements are taken 13 seconds after methane gas sucking. A timing of 100 seconds is required for purging the chamber before the second solenoid is turned-on. Devices temperature during operation was sampled with a thermal Flir-One camera and solenoid coil temperature was of $24.9^{\circ} \mathrm{C}$ after a continuous operation of 30 seconds. As hoses for emission sampling become larger time for sampling increases as well as energy consumption.
\end{abstract}

\section{Keywords}

Methane Detection, MQ-4 Sensor, Monitoring Head, Current Consumption

\section{Introduction}

Worldwide, approximately 5.51 million tonnes of garbage are generated daily [1], and a large percentage comes from food organic wastes. Anaerobic decomposition of such waste in dumps produces methane $\left(\mathrm{CH}_{4}\right)$, which is emitted into the atmosphere [2]. Methane monitoring and control represent an alternative to mitigate emissions that cause climate change [3]. Diaz [4] monitored $\mathrm{CH}_{4}$ emis- 
sions in two sites and found seasonal influence. Also $\mathrm{CH}_{4}$ emission differences appeared from dumping age and urban solid waste composition. Methane detection can avoid explosions and accidents inside landfills [5] [6].

Liu [7] and Peng [8] conducted research on methane monitoring of biogas from sewer lines. Draeger 6811960 and GEM2000/5000 infrared sensors (Land$\mathrm{Tec}$ ) were used but these sensors are expensive, and require a very large sample volume compared to MQ-4 sensors. Delgado and Rojas [9] designed a low-cost system using a MQ-4 sensor within an exposure chamber and a methane generator. The calibration of the MQ-4 sensor was made from 0 to $120 \mathrm{ppm}$, showing that the methane sensor is very sensitive in this range [10]. Humidity influences the sensitivity of the sensor, and when drying the sample, the upper limit of the MQ-4 range was improved at least ten times [11].

The cheap and easy programming MQ-4 sensor made it the best choice together with its long-life and calibration facilities [12]. The monitoring head can measure up to 8 different methane emissions on ducts or at different dump depths. As the equipment should work with an autonomy of 2 weeks taking two samples daily it is important to analyze current consumption, and optimize embedded system operation.

\section{Materials and Methods}

The entire head system was built around a MQ-4 methane gas sensor, that monitored the amount of methane present at different depths within the dump. The design has to be flexible enough so that it can measure also $\mathrm{CH}_{4}$ emissions in ducts and even in cattle barns. The measuring system head consists of a suction pump, solenoids, and a methane sensor. The pump sucks methane gas from the place where the emission is generated, and brings it to the sensor. The head monitoring system was visualized for obtaining its design by using the SolidWorks 2019 SP4.0 software from Dassault Systèmes ${ }^{\oplus}$.

\subsection{Mechanical Design}

SolidWorks is a friendly platform to develop 3D projects, obtaining manufacturing drawings, before being built. The mechanical design of the system head is shown in Figure 1. A duct with a stake-shaped tip at the end (not shown in the figure) is buried in the ground and connected to the lower base of the monitoring head Figure 1(1) \& Figure 2(1)). This tip was added to facilitate duct (Figure 2(3)) insertion within the landfill organic waste. In total there are 8 hoses, each fixed with a pneumatic connector to the duct at different depths ranging from $25 \mathrm{~cm}$ to $200 \mathrm{~cm}$. Gas coming from different depths should not be mixed, so each sampled gas is directed by a six mm diameter silicone hose towards a solenoid (Figure 1(2) \& Figure 2(2)). Once the sampled gas enters the hose (Figure 1(5) \& Figure 2(4)) it is sucked by the vacuum pump (Figure 1(3)) after turning-on the respective solenoid. A needle valve (Figure 1(8)) limits the flow towards the sampling chamber (Figure 1(4)) where the MQ-4 sensor is present. 


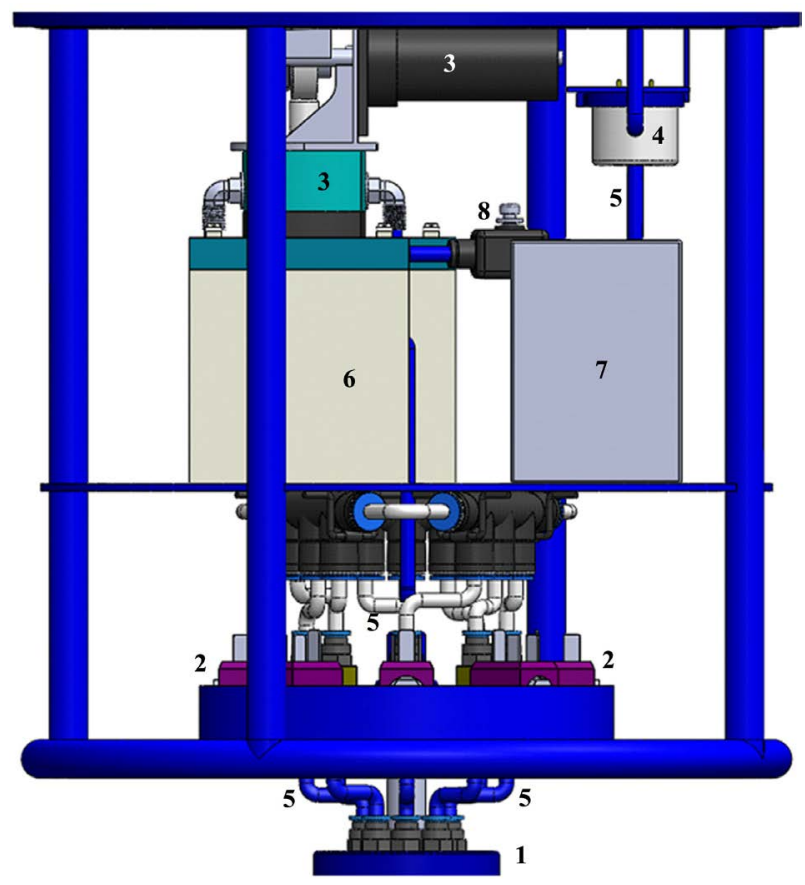

Figure 1. Entire head assembly consisting of (1) lower base, (2) solenoids, (3) vacuum pump, (4) sampling chamber, (5) hoses, (6) battery, (7) electronic circuit and (8) needle valve.

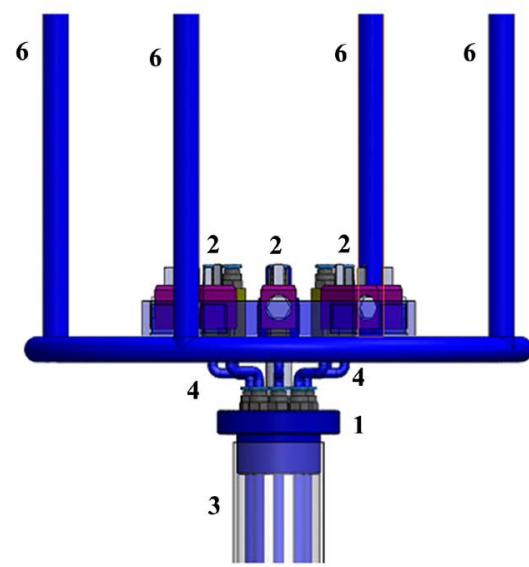

(a)

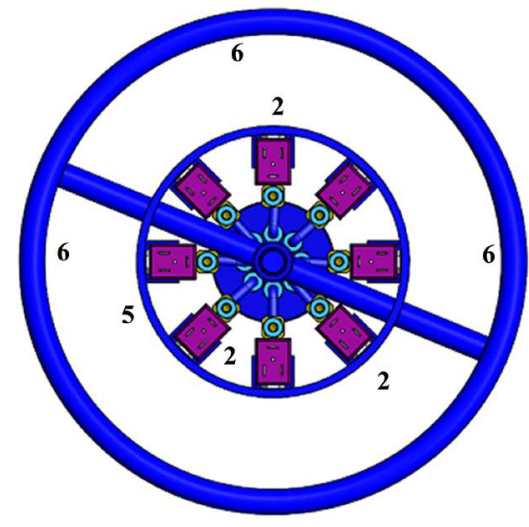

(b)

Figure 2. Entire head showing (a) lateral views and (b) top view of solenoids. Lower base (1), (2) solenoids, (3) buried duct, (4) hoses, (5) solenoid housing and (6) head external structure.

Once the MQ-4 sensor monitors the methane, the gas leaves the sampling chamber escaping to the atmosphere.

\subsection{Monitoring Head Devices}

The head system (Figure 1) consists of a suction pump (model 10D1125-1011053, Grainger, USA), solenoids, silicon hoses and a sensor within a sampling chamber. The self-lubricated and quiet 1/125 HP diaphragm pump provides a 
vacuum of $47.7 \mathrm{KPa}$. The maintenance-free unit is operated up to $24 \mathrm{VDC}$, handling $160 \mathrm{~mA}$ of current. To avoid mixing the samples obtained at each depth, normally closed solenoids (mod 116218-39, ARO Corp, Ohio, US) were used. Solenoids were turned-on by a MOSFET IRF730 supplied by 12 V DC. Solenoid coils require $760 \mathrm{~mA}$ of current as their coil resistance is of $14.5 \Omega$.

The gas-sensitive material used in the MQ-4 gas sensor is $\mathrm{SnO}_{2}$, and when methane gas exists in an environment, the conductivity of the sensor increases as the concentration of the gas increases. The MQ-4 gas sensor is highly sensitive to methane in concentrations from 300 to $10,000 \mathrm{ppm}$. The sensor can operate at temperatures from $-10^{\circ} \mathrm{C}$ to $50^{\circ} \mathrm{C}$ and consumes less than $150 \mathrm{~mA}$ at $5 \mathrm{~V}$. The sensor needs previous calibration depending on the environment it will be used. For precise calibration, once the sensor is powered-up, preheating lasts 24 hours until it reaches the right temperature. This operation is only done when the sensor is used for the first time and for further measurements values are acquired 15 seconds after turn-on.

An Arduino NANO microcontroller was used to acquire the data and control the turn-on of the solenoids and the suction pump. The system control also contained a micro-SD module for data storage and a RTC DS3231 to provide measurement timing and embedded system sleeping calls. The Arduino NANO was programmed in Arduino IDE and the calibration constants for the MQ-4 sensor were taken from Millan [12].

\subsection{Experimental Acquisition Variables}

Pump and solenoid operating time were determined by detecting when a small unicel (expanded polystyrene) sphere introduced the bottom of a hose arrived to the lower base of the monitoring head. This time corresponds the flow of methane gas from the point it enters the hose until it reaches the solenoid (Table 1). A presence capacitive sensor interrupted the microcontroller counting as a chronometer. The pump was connected to a $12 \mathrm{~V} \mathrm{DC}$ source and 10 measurements were acquired from each depth. The average and standard deviation of these times were obtained (Table 2).

Once the time constants were obtained the microcontroller was programmed. A real time clock (RTC) activated the acquisition system and the sampled values were saved in a MSD memory. During each sampling period the methane measurement from each one of the solenoids was acquired. After acquiring the values, the microcontroller turns the system off (sleep-mode) wasting null energy until the next alarm from the RTC appears. The acquisition timing can be programmed according to the user requirements but in this application it was set to monitor every 12 hours. A flow diagram of the acquisition routine is shown in Figure 3. An autonomy of 2 weeks taking two samples daily was required so current consumption of the circuit, solenoid and pump was monitored using a datalogger.

Device temperature cannot be hot in places where methane emissions are present as explosions can occur. Therefore, temperature at the solenoid coil was 
Table 1. Time taken by the unicel sphere to lift at different heights.

\begin{tabular}{ccccccccc}
\hline \multirow{7}{*}{ Test } & \multicolumn{7}{c}{ Time at different depths, sec } \\
\cline { 2 - 8 } & $\mathbf{2 5} \mathbf{~ c m}$ & $\mathbf{5 0} \mathbf{c m}$ & $\mathbf{7 5} \mathbf{c m}$ & $\mathbf{1 0 0} \mathbf{c m}$ & $\mathbf{1 2 5} \mathbf{c m}$ & $\mathbf{1 5 0} \mathbf{c m}$ & $\mathbf{1 7 5} \mathbf{c m}$ & $\mathbf{2 0 0} \mathbf{c m}$ \\
\hline 1 & 1.03 & 1.25 & 2.20 & 3.80 & 4.02 & 4.84 & 5.06 & 5.81 \\
2 & 0.78 & 1.32 & 2.55 & 3.70 & 4.19 & 4.89 & 5.22 & 5.85 \\
3 & 0.84 & 1.35 & 2.20 & 3.69 & 4.06 & 4.94 & 5.30 & 5.51 \\
4 & 0.76 & 1.27 & 2.25 & 3.69 & 3.98 & 4.88 & 5.15 & 5.35 \\
5 & 0.93 & 1.25 & 2.20 & 3.58 & 4.03 & 4.99 & 5.19 & 5.33 \\
6 & 0.85 & 1.26 & 2.20 & 3.71 & 4.10 & 4.80 & 5.15 & 5.34 \\
7 & 0.93 & 1.35 & 2.26 & 3.79 & 4.06 & 4.83 & 5.23 & 5.42 \\
8 & 0.95 & 1.27 & 2.16 & 3.55 & 4.08 & 4.90 & 5.29 & 5.73 \\
9 & 0.85 & 1.30 & 2.26 & 3.55 & 3.99 & 4.82 & 5.20 & 5.57 \\
10 & 0.86 & 1.32 & 2.12 & 3.74 & 4.06 & 4.90 & 5.12 & 5.63 \\
\hline
\end{tabular}

Table 2. Average time and current consumption taken by the monitoring head and datalogger to measure methane at different heights.

\begin{tabular}{ccccccccc}
\hline \multirow{2}{*}{ Test } & \multicolumn{7}{c}{ Time and current consumption at different depths } \\
\cline { 2 - 10 } & $\mathbf{2 5} \mathbf{~ c m}$ & $\mathbf{5 0} \mathbf{~ c m}$ & $\mathbf{7 5} \mathbf{~ c m}$ & $\mathbf{1 0 0} \mathbf{~ c m}$ & $\mathbf{1 2 5} \mathbf{c m}$ & $\mathbf{1 5 0} \mathbf{~ c m}$ & $\mathbf{1 7 5} \mathbf{~ c m}$ & $\mathbf{2 0 0} \mathbf{~ c m}$ \\
\hline Avg. time, s & 0.88 & 1.29 & 2.24 & 3.68 & 4.06 & 4.88 & 5.19 & 5.55 \\
Time std dev & 0.078 & 0.037 & 0.111 & 0.087 & 0.057 & 0.055 & 0.07 & 0.186 \\
Current, As & 0.84 & 1.23 & 2.13 & 3.49 & 3.86 & 4.64 & 4.93 & 5.27 \\
Current std dev & 0.09 & 0.027 & 0.29 & 0.096 & 0.082 & 0.078 & 0.09 & 0.35 \\
\hline
\end{tabular}

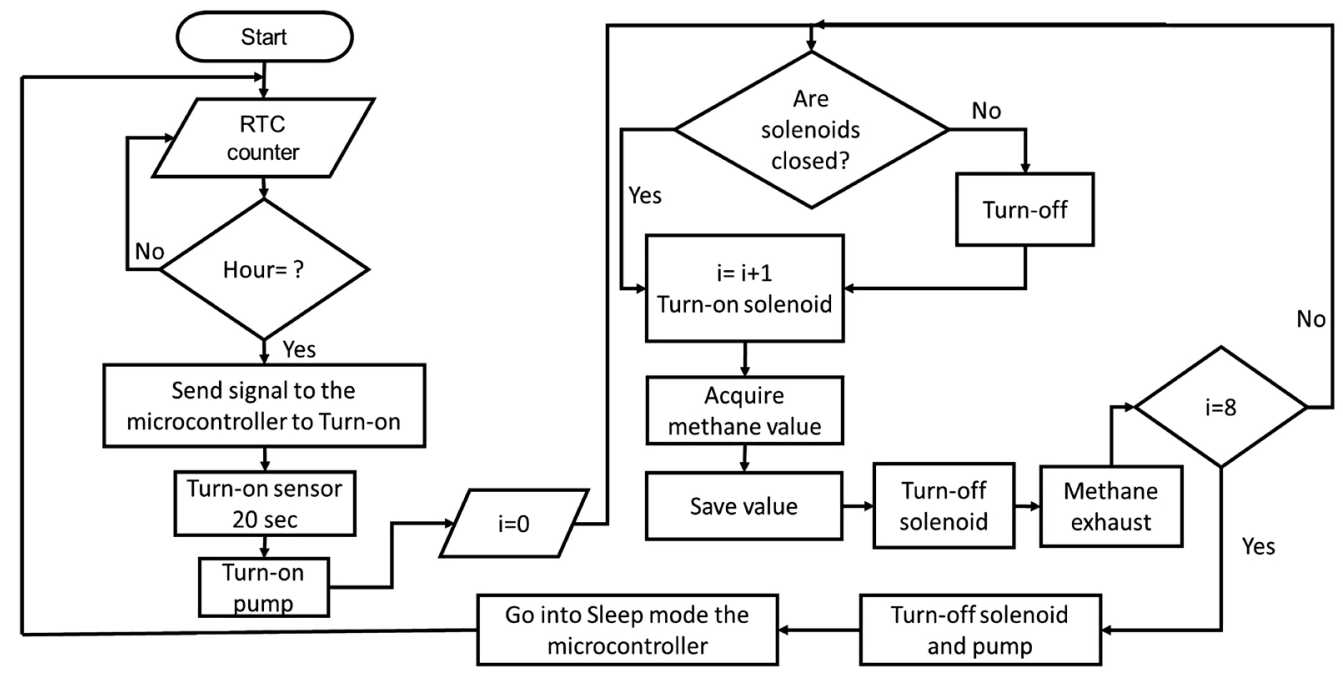

Figure 3. Acquisition routine flow diagram.

measured with a Flir-One thermal camera to assure that during operation it was colder than $30^{\circ} \mathrm{C}$. The Flir One software was installed within a smartphone for data collection. 


\section{Results and Discussion}

Table 1 shows the times acquired by a counter-timer stopped by the proximity sensor using an unicel sphere as the material being displaced within a hose once the suction pump operates. Time variation are due to the proximity sensor appreciation errors. For a depth of $25 \mathrm{~cm}$, the unicel sphere travel time is relatively shorter than at a depth of $200 \mathrm{~cm}$. Maximum variation of 0.087 between the ten samples was obtained at a depth of $100 \mathrm{~mm}$, Table 2. At a depth of $200 \mathrm{~cm}$, the average period it takes to suck the gas was of 5.55 seconds. In this case the programming variable was of 6 seconds. Current measurements vary with the hose length being 6.3 times greater with a $200 \mathrm{~cm}$ hose, than with a $25 \mathrm{~cm}$ hose. In order to save energy, the size of the hose should be considered. For an autonomy of 2 weeks, each sampling period will require to consider that 8 samplings are done, one per solenoid. For example, using $100 \mathrm{~cm}$ hoses, with 8 solenoids per sample every twelve hours, current consumption after 14 days will be of $781 \mathrm{~A}$. A battery of 0.217 Ah will provide the energy, but for longer battery life, deep discharges should be avoided and a 0.5 Ah battery employed. For the $200 \mathrm{~cm}$ hose, a consumption of 0.345 Ah was obtained so a bigger battery of 0.7 Ah can be considered.

Tests were carried out with methane gas to evaluate and compare the times acquired with the unicel sphere, in addition to the sampling chamber purging time. The monitoring system was turned-on with $12 \mathrm{~V} \mathrm{DC}$ batteries, using only one solenoid and with the pump always working. The $\mathrm{CH}_{4}$ sample gas concentration was generated by mixing $\mathrm{CH}_{4}$ and $\mathrm{N}_{2}$ through two mass flow controllers [13] [14], and fed to a tank connected to the hose. Once the tank gas became stable a needle valve was opened for gas injection through a silicone hose for 20 seconds with the pump and solenoid active. At the end of the gas detection, 90 seconds were allowed to remove $\mathrm{CH}_{4}$ from the chamber and a certain amount of time elapsed until it reached the initial readings.

The three tests with $\mathrm{CH}_{4}$ (Figure 4) showed that 5 seconds ( $\left.t_{1}\right)$ after gas application, the sensor detects that methane is present, reaching its maximum value after 13 seconds $\left(\mathrm{t}_{2}\right)$. After disconnecting the methane injection tank the measurement dropped after 45 seconds $\left(t_{3}\right)$. When the solenoid is closed, the gas gets concentrated and the measurement increases $\left(t_{4}\right)$. The evacuation of the gas lasts 40 seconds $\left(t_{5}\right)$ before the monitoring chamber was clean.

A previous work [15] showed that three operations are carried out for methane measurement in a landfill: baseline, sampling and purge. The first introduces atmospheric air to the chamber, the second measures methane and the purge, sucks the sampled gas away. It was reported that the baseline and purge operations can be avoided by careful operation resulting in energy saving and sampling time reduction. In our system a similar process is noted and if measurements are taken 13 seconds after pump and solenoid turn-on, optimum monitoring is achieved. Afterwards a timing of 100 seconds is required before the second solenoid is turned-on to allow complete purge from the chamber. 


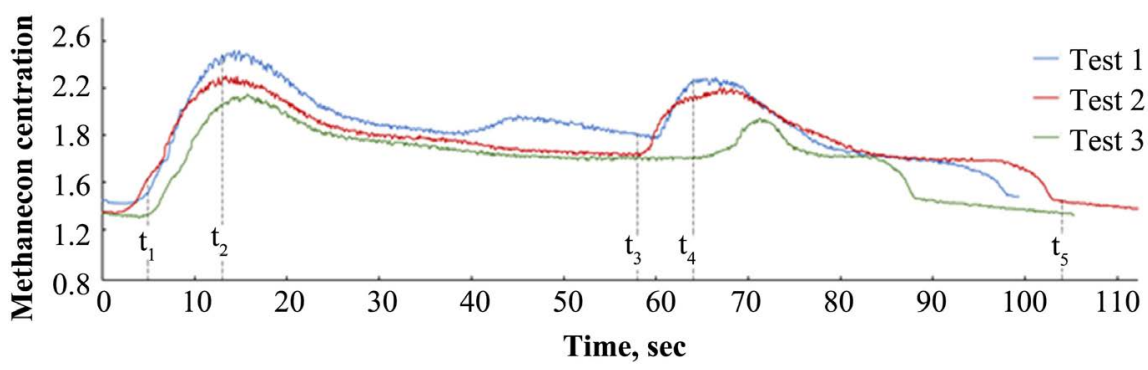

Figure 4. Methane gas monitoring.

The output voltage of a NDIR methane gas sensors with a reflecting vertical mirror was about $2.16 \mathrm{~V}$ at $0 \mathrm{ppm}$ methane gas concentration and decreases to 2.10 at $4000 \mathrm{ppm}$ [16]. The small voltage difference requires of differential processing to provide accurate measurements. Voltages of sensor modules operated for three years were attenuated by more than $50 \%$ from their initial values within the same gas concentration range [16]. NDIR sensor response time (from 10\% to 90\%) was approximately of 2.8 seconds [13] and require of temperature compensation to avoid drift and accuracy loss [17]. Comparatively, the MQ-4 sensor is durable without loss of accuracy or reproducibility, even after ten months of use [11].

The solenoid valve was turned-on for 10 minutes to verify that it did not overheat during the operating period. The coil temperature obtained during variable continuous operation is plotted in Figure 5. A good fit is given by a squared $\mathrm{T}$ equation as shown by the blue dot line, presenting a R2 over 0.89 . If the solenoid is turned-on for a period of 30 seconds, the coil temperature will reach $24.9^{\circ} \mathrm{C}$ and it is secure within the methane emissions environment. Figure 6 shows a Flir-One thermal image being the coil temperature of $45.2^{\circ} \mathrm{C}$ after 4 minutes of continuous measurement. The $45^{\circ} \mathrm{C}$ thermal temperature in Figure 6 is seen in yellow color.

\section{Conclusions}

This study concluded that the MQ-4 sensor worked properly for methane sensing in landfills at different depths. The monitoring head was designed to measure methane gas in different environments such as landfills, petrol and gas ducts and other places were $\mathrm{CH}_{4}$ emissions are present. The system uses a vacuum pump connected to a hose to suck the gas from the $\mathrm{CH}_{4}$ emitting place. Hose length represents the distance from the emission source to the sampling chamber. With a larger hose, the time taken by the gas to reach to the measuring chamber increases and energy consumption rises.

It was found that once methane arrived to the sampling chamber, the MQ-4 sensor increased its measurement achieving a maximum after 13 seconds. Ninety seconds after closing the solenoid, the chamber was completely purged and ready to begin another measurement. As the solenoid coil is turned-on for a maximum of 30 seconds its temperature rose to $24.9^{\circ} \mathrm{C}$ which is secure for explosive environments. 


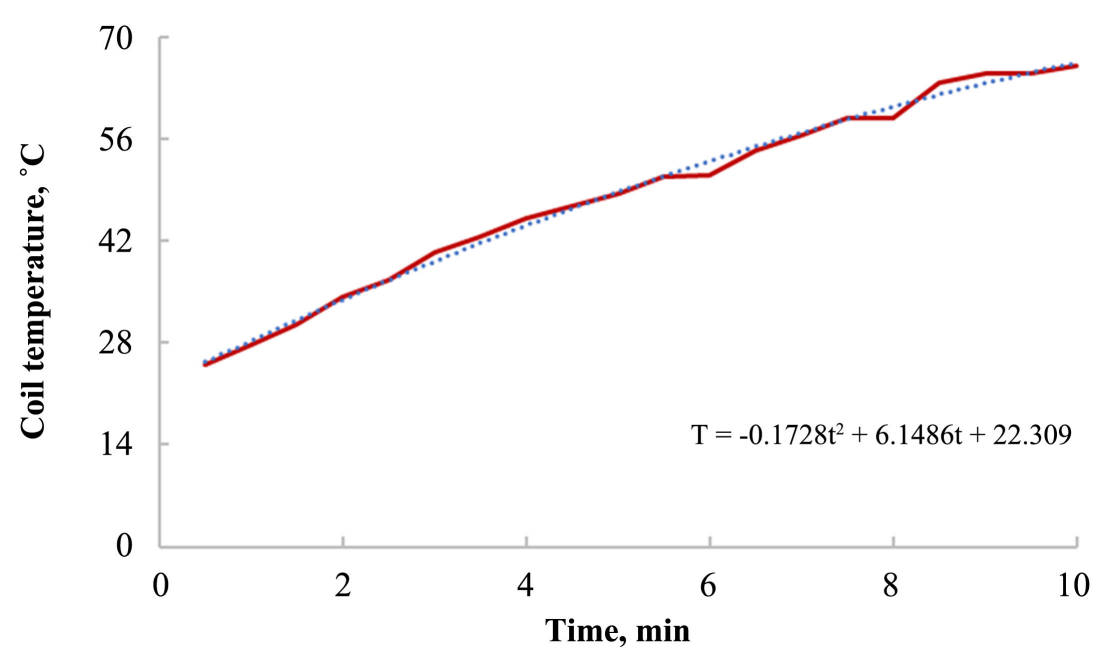

Figure 5. Solenoid coil temperature during 10 minutes of continuous operation.

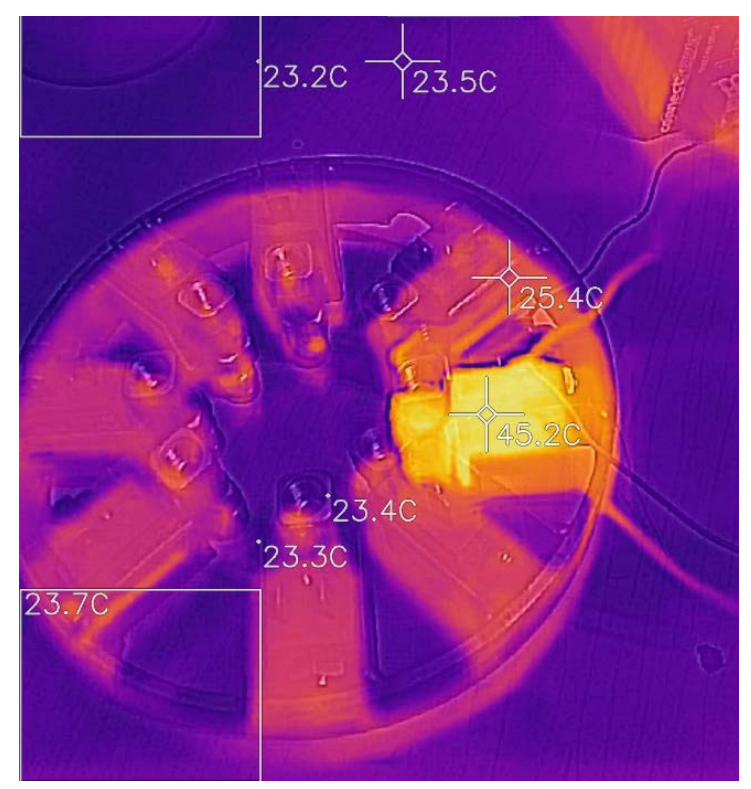

Figure 6. Thermal measurement of solenoids.

The embedded system routine is used only to acquire data and once it finishes, the microcontroller is sent to sleep. Data is saved in memory and alarms during excessive methane emissions can be generated for safety reasons. In the future, NDIR sensors will be used and compared with the MQ-4 sensor.

\section{Acknowledgements}

We would like to thank the DGIP department of the Universidad Autonoma Chapingo for funding of the project (\#20014-DTT-65) and to the laboratory personnel for providing and helping with the sensor calibration.

\section{Conflicts of Interest}

The authors declare no conflicts of interest regarding the publication of this paper. 


\section{References}

[1] Kaza, S., Yao, L.C., Bhada-Tata, P. and Van Woerden, F. (2018) What a Waste 2.0: A Global Snapshot of Solid Waste Management to 2050. World Bank, Washington, DC. https://openknowledge.worldbank.org/handle/10986/30317

[2] Rojas, V.N., Oropeza, P.I. and Nájera, A.H. (2009) Evaluación de medidas de control para disminuir las emisiones de metano y $\mathrm{CO}_{2}$ por residuos sólidos en México. II Simposio I Iberoamericano de Ingeniería de Residuos. Ciudad de México.

[3] Mønster, J., Kjeldsen, P. and Scheutz, C. (2019) Methodologies for Measuring Fugitive Methane Emissions from Landfills-A Review. Waste Management, 87, 835859. https://doi.org/10.1016/j.wasman.2018.12.047

[4] Díaz, A.L., Buenrostro, D.O., Mañón, S.M. and Hernández, B.M. (2017) Emisión de gases de efecto invernadero en dos sitios de disposición final de residuos sólidos urbanos en México. Ingeniería, Investigación y Tecnología, 18, 149-159. https://doi.org/10.22201/fi.25940732e.2017.18n2.013

[5] Liu, J., Tan, Q.L., Zhang, W.B., Xue, C.Y., Guo, T. and Xiong, J.J. (2011) Miniature Low-Power IR Monitor for Methane Detection. Measurement, 44, 823-831. https://doi.org/10.1016/j.measurement.2011.01.021

[6] Debeda, H., Dulau, L., Dondon, P., Menil, F., Lucat, C. and Massok, P. (1997) Development of a Reliable Methane Detector. Sensors and Actuators B: Chemical, 44, 248-256. https://doi.org/10.1016/S0925-4005(97)00164-0

[7] Liu, Y.W., Ni, B.J., Ganigue, R., Werner, U., Sharma, K.R. and Yuan, Z.G. (2015) Sulfide and Methane Production in Sewer Sediments. Water Research, 70, 350-359. https://doi.org/10.1016/j.watres.2014.12.019

[8] Peng, L., Ping, L., Cai, L.A. and Yi, M.Y. (2011) Design and Implementation of Safety Monitoring and Warning System of Toxic and Flammable Gas for Municipal Sewer Pipe Based on Nios-II and GPRS. 6th IEEE Joint International Information Technology and Artificial Intelligence Conference, Chongqing, 20-22 August 2011, 394-397. https://doi.org/10.1109/ITAIC.2011.6030357

[9] Delgado, C.A. and Rojas, B.O. (2015) Construcción de un sistema de bajo costo para el uso y evaluación de sensores semiconductores para gases. Educación QuÍmica, 26, 299-306. https://doi.org/10.1016/j.eq.2015.07.001

[10] Palacios, J., Falcon, N. and Munoz, E. (2015) Design, Construction and Automation of Sensors for Monitoring Greenhouse Gases in the Lower Troposphere. Ingenius. Revista de Ciencia y Tecnología, 14, 21-29.

[11] Yang, S.C., Liu, Y.K., Wu, N., Zhang, Y.X., Svoronos, S. and Pullammanappallil, P. (2019) Low-Cost, Arduino-Based, Portable Device for Measurement of Methane Composition in Biogas. Renewable Energy, 138, 224-229.

https://doi.org/10.1016/j.renene.2019.01.083

[12] Marco, M.F. and Delgado, G.J. (2016) Diseño e implementación de un sistema de medida de gases con Arduino [Design and Development of a Gas Monitoring System with Arduino]. Universidad de Zaragoza, España.

http://zaguan.unizar.es/record/59102

[13] Jia, X.N., Roels, J., Baets, R. and Roelkens, G. (2019) On-Chip Non-Dispersive Infrared $\mathrm{CO}_{2}$ Sensor Based On an Integrating Cylinder. Sensors, 19, 4260. https://doi.org/10.3390/s19194260

[14] Zhu, Z.P., Xu, Y.H. and Jiang, B.Q. (2012) A One ppm NDIR Methane Gas Sensor with Single Frequency Filter Denoising Algorithm. Sensors, 12, 12729-12740. https://doi.org/10.3390/s120912729 
[15] Fay, C., Doherty, A.R., Beirne, S., Collins, F., Foley, C., Healy, J., Kiernan, B.M., Lee, H., Maher, D., Orpen, D., Phelan, T., Qiu, Z., Zhang, K., Gurrin, C., Corcoran, B., O'Connor, N.E., Smeaton, A.F. and Diamond, D. (2011) Remote Real-Time Monitoring of Subsurface Landfill Gas Migration. Sensors, 11, 6603-6628.

https://doi.org/10.3390/s110706603

[16] Park, J.S. and Yi, S.H. (2011) Nondispersive Infrared Ray $\mathrm{CH}_{4}$ Gas Sensor Using Focused Infrared Beam Structures. Sensors and Materials, 23, 147-158. https://doi.org/10.18494/SAM.2011.681

[17] Park, J.S. and Yi, S.H. (2010) Temperature Compensated NDIR $\mathrm{CH}_{4}$ Gas Sensor with Focused Beam Structure. Procedia Engineering, 5, 1248-1251.

https://doi.org/10.1016/j.proeng.2010.09.339 